\title{
Optical properties of D-serine doped TGS crystals for pyroelectric sensors*
}

\author{
V.YU. KURLYAK ${ }^{1}$, V.Yo. STADNYK ${ }^{1}$, B.V. ANDRIYEVSKY ${ }^{2 \dagger}$, M.O. ROMANYUK ${ }^{1}$, Z.O. KOHUT ${ }^{3}$, \\ V.M. GABA ${ }^{3}$ \\ ${ }^{1}$ The Ivan Franko National University of Lviv, 8 Kyrylo-and-Mefodii St., UA-79005 Lviv, Ukraine \\ ${ }^{2}$ Faculty of Electronics and Computer Sciences, Koszalin University of Technology, \\ 2 Śniadeckich St., PL-75-453, Koszalin, Poland \\ ${ }^{3}$ National University "Lviv Politechnic”, 12 Bandera St., UA-79013 Lviv, Ukraine
}

\begin{abstract}
Refractive and birefringence indices in the range of transparency of 300 to $700 \mathrm{~nm}$ for triglycine sulphate crystals doped with D-serine molecules have been measured in the temperature range of $290 \mathrm{~K}$ to $340 \mathrm{~K}$. The obtained optical properties are discussed together with characteristic electrical features of these materials used as pyroelectric sensors for measurement of temperature. The experimental results obtained in this study will be necessary as the reference data for comparison with the calculated refractive indices of TGS + D-serine on the basis of density functional theory. Determination of the proper position of D-serine, will reveal the features of TGS + D-serine crystal structure necessary to achieve stable unipolarity.
\end{abstract}

Keywords: pyroelectric sensors; ferroelectrics; triglycine sulphate; optical properties

(C) Wroclaw University of Technology.

\section{Introduction}

Sensors that can convert optical radiation into the electric energy are known as pyroelectric sensors. A capacitor-like device with a dielectric layer in the form of crystalline plate is a sensitive part of the pyroelectric sensor. Thin layer of the light absorbing substance is deposited on one of the electrodes. As a result, the optical energy absorbed by this substance is converted into the thermal one which consequently increases temperature of the crystal. This leads to the change in the pyroelectric polarization of the crystal plate which can be recorded and used for the measurement of sensor temperature. Commonly, several such pyroelectric sensors are connected in series to create one measuring device. This may guarantee the insensitivity of the measuring sensor to ambient temperature changes and enable the alternating output voltage

\footnotetext{
${ }^{*}$ This paper was presented at the $38^{\text {th }}$ International Microelectronics and Packaging Conference IMAPS-CPMT, Poland, September 21 - 24, 2014. Rzeszów-Czarna.

†E-mail: bohdan.andriyevskyy@tu.koszalin.pl
}

when moving the focused image of an object on the sensitive surface of the sensor.

The spectral sensitivity of the sensor is determined by the absorption capacity of the pyroelectric coating plate in a certain frequency range of electromagnetic radiation. It is also influenced by optical filters installed in the front of the sensitive element.

The main parameters of pyrosensors are dependent on the material constants of the sensitive crystalline plate of the device. Relations for the figure of merit of a pyroelectric sensor acting in the mode of impulse radiation and empty circle were presented in the literature [1-3]:

$$
M_{1}=\frac{\gamma}{c_{1}}
$$

In the mode of empty circle and low flux:

$$
M_{2}=\frac{\gamma}{c_{1}} \varepsilon \text { and } M_{3}=\frac{\gamma}{c_{1}}(\varepsilon \cdot \operatorname{tg} \delta)^{0.5}
$$

where $\varepsilon$ is dielectric permittivity, $\gamma$ is pyroelectric coefficient, $c_{1}$ is thermal capacity of a unit volume. 
The figure of merit $\mathrm{M}_{1}$ is a transforming coefficient at low load resistance, $\mathrm{M}_{2}$ is the same but at high resistance, and $\mathrm{M}_{3}$ characterizes the detecting ability of the sensor.

Materials for pyroelectric sensors should have the values $\mathrm{M}_{1}, \mathrm{M}_{2}$ and $\mathrm{M}_{3}$ as high as possible. The choice of pyroelectric material for the sensor depends not only on the figure of merit but is influenced by other factors. The crucial ones are:

1. temperature of ferroelectric phase transition $\mathrm{T}_{\mathrm{C}}$, which determines the temperature and dynamic range of the sensor;

2. mechanical strength and hydrophobicity;

3. magnitude of acoustic losses, which corresponds to the attenuation of elastic vibrations;

4. stability of single domain state;

5. level of additional noises;

6. time stability of parameters;

7. simplicity of technology of the sensitive element;

8. possibility of manufacturing thin layers, while preserving the characteristics of the bulk material;

9. possibility of manufacturing sensitive elements of sensors with large dimensions.

TGS crystals are among the most widely used pyro-active materials [4-12]. Despite the fact that almost every year tens of thousands of new synthesized pyroactive crystals, ceramics and polymers are synthesized, TGS is currently the material with the highest figure of merit $\mathrm{M}_{3}$, which characterizes the detecting ability of sensors. Efforts to remove the drawbacks inherent to TGS are constantly undertaken. The main aims of these efforts are to obtain a stable single domain structure of TGS, insensitive to temperature, climate and radiation changes, and able to extend the temperature range of the pyroelectric sensor sensitivity.

Since pure TGS and isomorphic crystals are "soft" ferroelectric materials with low coercive fields, they have a domain structure with unstable unipolarity. In order to obtain stronger ferroelectric activity they are doped during the crystal growth by ions of chromium, copper, nickel or the glycine molecules of TGS are replaced by the structurally similar ones, such as L- $\alpha$-alanine [13].

Presently, pure TGS are practically not used for pyroelectric sensors and the TGS doped crystal is one of the most often used for the fabrication of highly sensitive pyroelectric devices operating at low frequency modulation.

The introduction of structurally similar organic impurities into TGS crystal causes fixation of one of the polarizations $+\mathrm{P}_{\mathrm{c}}$ or $-\mathrm{P}_{\mathrm{c}}$ and appearance of a bias field $\mathrm{E}_{\mathrm{b}}$ in the crystal. As a result, the dielectric parameters of the doped crystals undergo minor changes during spontaneous aging that is essential in practical use of these crystals.

It is known that the molecular serine $\left(\mathrm{C}_{3} \mathrm{O}_{3} \mathrm{NH}_{7}\right)$ exists in two stereoisomeric forms, $\mathrm{L}$ and $\mathrm{D}$, which differ in the sign of optical activity. Stereoisomers are isomeric molecules that have the same molecular formula and sequence of bonded atoms, but that differ only in the threedimensional orientation of their atoms in space (L- and D-serine molecules may be converted one to another by applying the symmetry operation of mirror reflection) [14-18]. In crystals, L- or D-serine may exist in the monoprotonated, $\mathrm{CH}_{2}(\mathrm{OH}) \mathrm{CH}\left(\mathrm{NH}_{3}\right) \mathrm{COOH}^{+}$, and zwitterion, $\mathrm{CH}_{2}(\mathrm{OH}) \mathrm{CH}\left(\mathrm{NH}_{3}\right) \mathrm{COO}$, forms [15-18]. For example, in one of the serine containing crystal $\left(\mathrm{C}_{3} \mathrm{O}_{3} \mathrm{NH}_{7}\right)_{2} \mathrm{H}_{3} \mathrm{PO}_{4} \mathrm{H}_{2} \mathrm{O} \quad[17,18]$, the corresponding lengths of the bonds $\mathrm{C}-\mathrm{C}$ and $\mathrm{C}-\mathrm{N}$ in both forms of serine molecule (monoprotonated and zwitterion) are similar and are equal to $\mathrm{d}_{\mathrm{C}-\mathrm{C}}=1.514 \AA$ and $1.527 \AA$ and $\mathrm{d}_{\mathrm{C}-\mathrm{N}}=1.486 \AA$ and $1.497 \AA$, respectively. However, due to deprotonation of the carboxyl group in zwitterion, two $\mathrm{C}-\mathrm{O}$ bonds become close to each other, i.e. $1.250 \AA$ and $1.254 \AA$. The later magnitudes are close to the averaged $\mathrm{C}-\mathrm{O}$ distances in the carboxyl group $\mathrm{COOH}$ of the monoprotonated ion $\mathrm{CH}_{2}(\mathrm{OH}) \mathrm{CH}\left(\mathrm{NH}_{3}\right) \mathrm{COOH}^{+}, 1.205 \AA$ and $1.316 \AA$.

In a TGS crystal with admixture of L-serine, these two forms of serine are connected one to another by hydrogen bonds. It was revealed that a relatively small amount of L-serine in the freshly prepared TGS + L-serine crystal increases 
substantially its spontaneous polarization [16, 19]. Further increase of the concentration of serine admixture leads to a decrease of spontaneous polarization and increase of the coercive and bias electric fields. TGS + L-serine crystals grow asymmetrically along the b-axis when compared to their initial form. It was suggested in [19] that distribution of L-serine admixture is inhomogeneous. The admixture inhibits the growth of the crystal in b-axis direction, so that more impurities are embedded into the crystal in its less developed side. It was found that the internal electric field leads to the same effect as the external field applied to the crystal. Since the bias electric field $\mathrm{E}_{\mathrm{b}}$ is higher for the growth of $\left(\begin{array}{lll}0 & 0 & 1\end{array}\right)$ pyramid than that of $\left(\begin{array}{lll}1 & 1 & 0\end{array}\right)$, the conclusion was derived that more impurities are embedded in the $\left(\begin{array}{lll}0 & 0 & 1\end{array}\right)$ pyramid during the crystal growth.

It was also found that for crystals with a low impurity concentration, maximum dielectric permittivity $\varepsilon_{\max }$ is smaller than for the pure TGS crystal and the value of $\varepsilon_{\text {max }}$ decreases with increasing concentration of serine in the solution. The Curie temperature $\mathrm{T}_{\mathrm{C}}$ of TGS $+\mathrm{L}$-serine crystal is lower than that for pure TGS crystal. The temperature dependences of spontaneous polarization $\mathrm{P}_{\mathrm{S}}(\mathrm{T})$ and coercive field $\mathrm{E}_{\mathrm{c}}(\mathrm{T})$ of $\mathrm{TGS}+\mathrm{L}$-serine crystal show that spontaneous polarization decreases and coercive field increases with an increase of the $\mathrm{L}$-serine concentration in the growth solution.

We have not found similar reference information on TGS + D-serine crystal, but one should expect similar effects to those observed in TGS + L-serine, described above. This suggestion is based on the fact that TGS + D-serine crystals grow asymmetrically with respect to the seed along b-axis, similarly to that observed for TGS + L-serine crystal, though the asymmetry in case of TGS + D-serine was found to be developed in the opposite direction of b-axis [20].

Optical and refractive methods are known to be a sensitive instrument for studying of the ferroelectric properties of crystals [21]. In the present study, the characteristics of optical refractive properties of TGS crystals doped with D-serine molecules in the temperature range of $290 \mathrm{~K}$ to $340 \mathrm{~K}$ have been obtained and discussed in view of their application as pyroelectric sensors.

\section{Experimental}

For optical measurements, the parallel plate samples of TGS crystal doped with $5 \% \mathrm{D}$-serine were cut from a $\left(\begin{array}{lll}0 & 0 & 1\end{array}\right)$ pyramid in the most developed part of the single crystal grown close to its seed region. Three kinds of the plates orientations, i.e. $\left(\begin{array}{lll}1 & 0 & 0\end{array}\right),\left(\begin{array}{lll}0 & 1 & 0\end{array}\right)$, and $\left(\begin{array}{lll}0 & 0 & 1\end{array}\right)$, were cut for the measurements of the birefringence $\Delta \mathrm{n}_{\mathrm{i}}$ of the material in three directions, $\mathrm{I}=\mathrm{x}, \mathrm{y}, \mathrm{z}$. For the study of refractive indices $\mathrm{n}$, the plates of $0.1 \mathrm{~mm}$ to $0.2 \mathrm{~mm}$ thickness were used, whereas for the measurements of birefringence $\Delta \mathrm{n}$, the plates of $2 \mathrm{~mm}$ to $3 \mathrm{~mm}$ thickness were employed. The crystal orientation of the plates was checked by conoscopic observation with $\mathrm{He}-\mathrm{Ne}$ laser beam and additionally using a polarization microscope.

Dispersion of refractive index $n(\lambda)$ of a crystal were measured using the spectral interferometric Obreimov method [22]. In the method, a plane optical wave incident on the edge of a parallel plate crystal is splitting into two beams. Along the edge of geometrical shadow, the light beams passing through the crystals and environment are overlapping due to diffraction and they interfere. The corresponding difference of optical paths $\Delta$ depends on the refractive index $\mathrm{n}$ of a crystal and its geometric thickness d [22]:

$$
\Delta=d(n-1)
$$

The refractive index $n$ of a crystal may be presented as:

$$
n(\lambda, T)=1+k \lambda / d(T)
$$

The crystal sample thickness $d$ is usually measured using a quartz dilatometer. The interference order $\mathrm{k}$ is obtained from the same relation 4 using results of separate measurements of $n$ by the immersion Obreimov method at one wavelength $\lambda$ [22]. Measurements of refractive indices using this method can be performed in the spectral range 
of crystal transparency 290 to $750 \mathrm{~nm}$ and temperature range $77 \mathrm{~K}$ to $950 \mathrm{~K}$ with an accuracy near $\delta \mathrm{n} \approx 2 \times 10^{-4}$.

\section{Results and discussion}

We have found that the TGS grown with addition of $\mathrm{D}$-serine are characterized by smaller refractive indices $n_{x}$ and $n_{z}$ and larger $n_{y}$ one in comparison with pure TGS, where $\mathrm{x}, \mathrm{y}$, and $\mathrm{Z}$ are directions of the crystal and physical axes of the crystal (Fig. 1). The relations between refractive indices, $\mathrm{n}_{\mathrm{x}}>\mathrm{n}_{\mathrm{z}}>\mathrm{n}_{\mathrm{y}}$, and their corresponding dispersions, $\mathrm{dn}_{\mathrm{x}} / \mathrm{d} \lambda>\mathrm{dn}_{\mathrm{y}} / \mathrm{d} \lambda>\mathrm{dn}_{\mathrm{z}} / \mathrm{d} \lambda$, for the TGS + D-serine crystals remain the same as those for pure TGS. Differences of refractive indices of TGS $+\mathrm{D}$-serine and TGS crystals for the wavelength $\lambda=300 \mathrm{~nm}$ and $700 \mathrm{~nm}$ are as follows: $\mathrm{n}_{\mathrm{x}}^{\text {(TGS }+\mathrm{D}-\text { serine })}-\mathrm{n}_{\mathrm{x}}^{(\mathrm{TGS})}=$ $-2.9 \times 10^{-3}$ and $-2.0 \times 10^{-3}, \mathrm{n}_{\mathrm{y}}^{(\mathrm{TGS}+\mathrm{D}-\text { serine })}-$ $\mathrm{n}_{\mathrm{y}}^{(\mathrm{TGS})}=3.6 \times 10^{-3}$ and $2.8 \times 10^{-3}, \mathrm{n}_{\mathrm{z}}^{(\mathrm{TGS}+\mathrm{D}-\text { serine })}$ $-\mathrm{n}_{\mathrm{z}}^{(\mathrm{TGS})}=-2.8 \times 10^{-3}$ and $-1.8 \times 10^{-3}$. These results indicate that the degree of anisotropy of optical indicatrix of TGS + D-serine, determined as the value of maximum refractive indices difference, is smaller than for the pure TGS (Fig. 1). One of possible explanations of this result could be, in principle, the random positions of $\mathrm{D}$-serine molecules in TGS + D-serine crystal. This, however, is only one explanation among many others. Other probable suggestion proposed earlier for TGS + L-serine crystals is location of D-serine in the place of glicine-I unit in pure TGS [19].

Analysis of the dependences $n_{i}(\lambda)$ for TGS + $\mathrm{D}$-serine by the model of effective ultraviolet oscillators has been performed and the increase in $\Delta \lambda_{0 \mathrm{y}}=8.5 \mathrm{~nm}$ and decrease in $\Delta \lambda_{0 \mathrm{x}}=-5.2 \mathrm{~nm}$ and $\Delta \lambda_{0 \mathrm{z}}=-4.3 \mathrm{~nm}$ have been obtained in relation to the pure TGS. These results are in qualitative accordance with the changes of refractive index anisotropy discussed above.

It is known that the molecular refraction:

$$
R=\frac{n^{2}-1}{n^{2}+2} \frac{M}{\rho}=\frac{4}{3} \pi N_{A} \alpha_{E}
$$

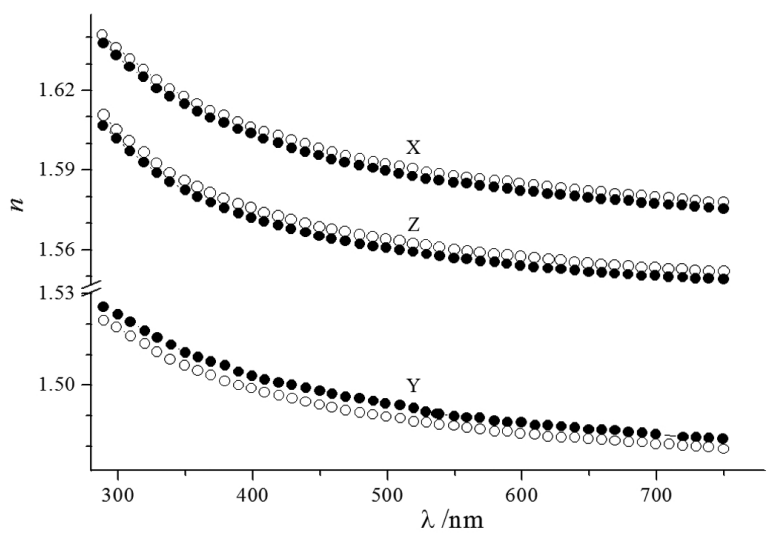

Fig. 1. Dispersion of refractive indices $n_{i}(\lambda)(i=x, y, z)$ of pure TGS (open circles) and TGS $+\mathrm{D}$-serine (closed circles) crystals at ambient temperature, $\mathrm{T}=293 \mathrm{~K}$.

of TGS, being an additive value, is composed of approximately equal contributions of four molecular groups: (1) $\mathrm{NH}_{3}$ ion, (2) glicine core, (3) carboxyl ion and (4) $\mathrm{SO}_{4}$ ion with hydrogen bonds. Addition of D-serine $\mathrm{CH}_{2}(\mathrm{OH}) \mathrm{CH}\left(\mathrm{NH}_{2}\right) \mathrm{COOH}$ into the TGS crystal or substitution of the glicine $\mathrm{CH}_{2} \mathrm{NH}_{2} \mathrm{COOH}$ by D-serine should increase the molecular refraction $\mathrm{R}$ of $\mathrm{TGS}+\mathrm{D}$-serine. If, however, one takes into account corresponding increase in the molecular weight $\mathrm{M}$, the averaged refractive index $n$ of TGS + D-serine may be expected unchanged or changed only slightly, according to the relation 5. The latter conclusion is generally supported by the experimental results obtained (Fig. 1).

Temperature changes of the refractive indices $n_{i}$ $(\mathrm{i}=\mathrm{x}, \mathrm{y}, \mathrm{z})$ of TGS $+\mathrm{D}$-serine are linear in the paraelectric phase and nonlinear in the ferroelectric one (Fig. 2). The largest temperature changes of refractive indices in the polar phase are observed for the x-polarization. The relation $\partial \mathrm{n}_{\mathrm{x}} / \partial \mathrm{T}>$ $\left|\partial \mathrm{n}_{\mathrm{z}} / \partial \mathrm{T}\right|>\left|\partial \mathrm{n}_{\mathrm{y}} / \partial \mathrm{T}\right|$ takes place for TGS + D-serine, which is the same as for pure TGS. The only difference is in the magnitudes of $\partial \mathrm{n}_{\mathrm{i}} / \partial \mathrm{T}$, which are much smaller than those for pure TGS. In other words, insertion of the D-serine admixture leads to a decrease in the temperature sensitivity of refractive indices $\mathrm{n}_{i}(\mathrm{~T})$. On the phenomenological level, this result is obtained due to the influence 
of internal stresses and decrease in spontaneous electrical polarization of the doped crystals [2325]. On the microscopic level, the results observed may be associated with the fact that all glicine molecular groups in TGS are almost plane and are oriented perpendicularly to the polar y-axis, what determines the anisotropy of refractive indices of TGS, $\mathrm{n}_{\mathrm{x}}>\mathrm{n}_{\mathrm{z}}>\mathrm{n}_{\mathrm{y}}$. If the $\mathrm{D}$-serine molecular group is oriented along the polar axis in TGS $+\mathrm{D}$-serine, this may result in a change in the corresponding optical anisotropy due to the relative increase of $n_{y}$ and decrease of $\mathrm{n}_{\mathrm{x}}$ and $\mathrm{n}_{\mathrm{z}}$, which is really observed.

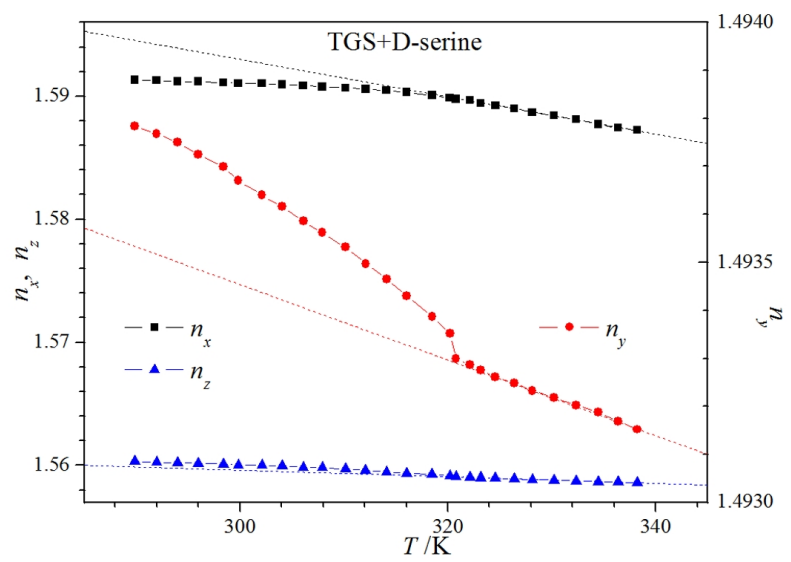

Fig. 2. Temperature dependences of refractive indices $\mathrm{n}_{\mathrm{i}}(\mathrm{T})(\mathrm{i}=\mathrm{x}, \mathrm{y}, \mathrm{z})$ of TGS $+\mathrm{D}$-serine at the wavelength $\lambda=500 \mathrm{~nm}$.

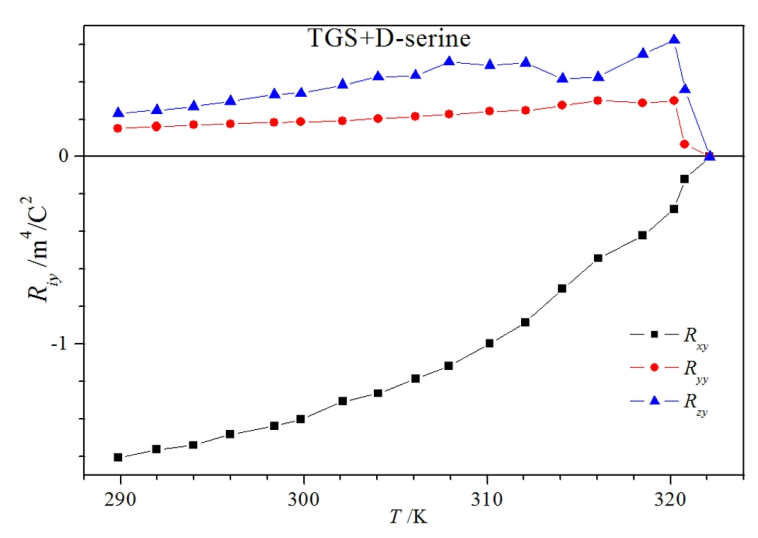

Fig. 3. Temperature dependences of coefficients of quadratic EOE $\mathrm{R}_{\mathrm{iy}}(\mathrm{i}=\mathrm{x}, \mathrm{y}, \mathrm{z})$ of $\mathrm{TGS}+\mathrm{D}$ serine at the wavelength $\lambda=500 \mathrm{~nm}$.
Changes in the dependences $n_{i}(T)$ observed at the Curie temperature, $T_{C}=322 \mathrm{~K}$ (Fig. 2) may be associated with the ferroelectric phase transition resulting in the spontaneous electrooptic effect (EOE) in the crystal. Because of the presence of the inversion symmetry operation in the structure of paraelectric phase of TGS, the liner EOE is impossible [26]. For this reason, the spontaneous increments of refractive index of TGS may be presented at first approximation in the form:

$$
\delta n_{i}=\frac{1}{2} n_{i}^{3} R_{i y} P_{y}^{2}, i=x, y, z
$$

where $R_{i y}$ are coefficients of the quadratic EOE, $P_{y}$ is the spontaneous polarization, $\mathrm{P}_{\mathrm{s}}$ along $\mathrm{y}$-axis of TGS and $n_{i}$ are refractive indices. The coefficients of quadratic EOE, $\mathrm{R}_{\mathrm{iy}}$ were calculated using the relation 6 in the temperature range of $290 \mathrm{~K}$ to $322 \mathrm{~K}$ (Fig. 3). For the calculations of $\mathrm{R}_{\mathrm{iy}}$, the temperature dependence of square of spontaneous polarization has been taken as $\mathrm{P}_{\mathrm{y}}^{2}=\mathrm{a}\left(\mathrm{T}-\mathrm{T}_{\mathrm{C}}\right)$, where the coefficient a is equal to $3 \times 10^{-5} \mathrm{C}^{2} /\left(\mathrm{m}^{4} \cdot \mathrm{K}\right)[27,28]$.

Although the relation between principal refractive indices of TGS + D-serine is the same as for TGS, $\mathrm{n}_{\mathrm{x}}>\mathrm{n}_{z}>\mathrm{n}_{\mathrm{y}}$, the temperature dependences of spontaneous temperature changes $\delta \mathrm{n}_{\mathrm{i}}^{(\mathrm{s})}$ (differences between experimental points and corresponding dashed lines in Fig. 2 and Fig. 4) and corresponding coefficients of quadratic EOE, $R_{i y}$ are different (Fig. 2-5).

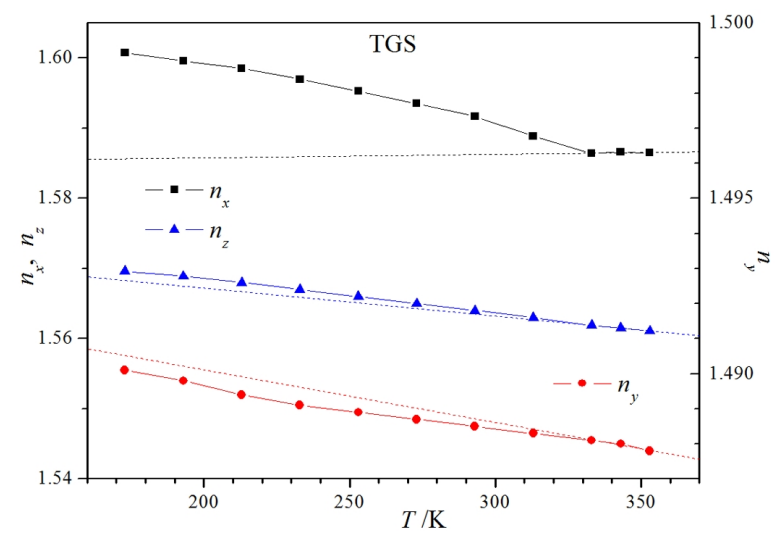

Fig. 4. Temperature dependences of refractive indices $\mathrm{n}_{\mathrm{i}}(\mathrm{T})(\mathrm{i}=\mathrm{x}, \mathrm{y}, \mathrm{z})$ of TGS at the wavelength $\lambda=$ $500 \mathrm{~nm}$. 


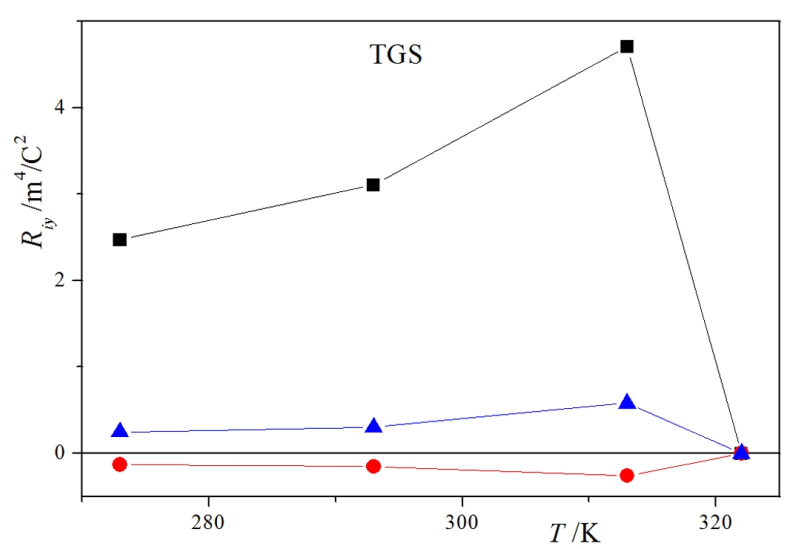

Fig. 5. Temperature dependences of coefficients of quadratic EOE $R_{\text {iy }}(i=x, y, z)$ of TGS at the wavelength $\lambda=500 \mathrm{~nm}$.

The values of birefringence $\Delta n_{i}=n_{j}-n_{k}$ $(\mathrm{i}, \mathrm{j}, \mathrm{k}=\mathrm{x}, \mathrm{y}, \mathrm{z})$ of TGS $+\mathrm{D}$-serine are different from those for the pure TGS (Fig. 1). At the same time, the relations between the dispersions of principal birefringence remain the same as those for pure TGS, $\left|\partial \Delta \mathrm{n}_{\mathrm{z}} / \partial \lambda\right|>\left|\partial \Delta \mathrm{n}_{\mathrm{x}} / \partial \lambda\right|>$ $\left|\partial \Delta \mathrm{n}_{\mathrm{y}} / \partial \lambda\right|$. It is seen from Fig. 1 that the relations $\Delta \mathrm{n}_{\mathrm{x}}^{(\mathrm{TGS}+\mathrm{D}-\text { serine })}<\Delta \mathrm{n}_{\mathrm{x}}^{(\mathrm{TGS})}$ and $\Delta \mathrm{n}_{\mathrm{z}}^{(\mathrm{TGS}+\mathrm{D}-\text { serine })}$ $<\Delta \mathrm{n}_{\mathrm{Z}}^{\text {(TGS) }}$ take place. The difference between the birefringences $\Delta \mathrm{n}_{\mathrm{y}}^{(\mathrm{TGS}+\mathrm{D} \text {-serine) }}-\Delta \mathrm{n}_{\mathrm{y}}^{(\mathrm{TGS})}$ changes between positive $5.59 \times 10^{-4}$ (at $\lambda=300 \mathrm{~nm}$ ) and negative $-7.32 \times 10^{-4}$ (at $\lambda=750 \mathrm{~nm}$ ) value, depending on the wavelength region. In the wavelength region of $\lambda \approx 365 \mathrm{~nm}$, the equality of birefringences $\Delta \mathrm{n}_{\mathrm{y}}^{(\mathrm{TGS}+\text { Dserine })}=\Delta \mathrm{n}_{\mathrm{y}}^{(\mathrm{TGS})}=0.03089$ takes place. We have found that the absolute value of temperature change of birefringence $\left|\mathrm{d}\left(\Delta \mathrm{n}_{\mathrm{y}}\right) / \mathrm{dT}\right|$ for TGS $+\mathrm{D}$-serine is much smaller than that for pure TGS. This results in a displacement of the spectral point, where $\Delta \mathrm{n}_{\mathrm{y}}^{(\mathrm{TGS}+\text { Dserine })}=\Delta \mathrm{n}_{\mathrm{y}}^{(\mathrm{TGS})}$, to the shorter wavelengths when temperature decreases to room temperature $(T=293 \mathrm{~K})$.

One can expect that different amounts of D-serine admixture will lead to monotonous changes in refractive indices and birefringence of TGS + D-serine, that would be rather a common result. However, the presence of the spectral point, where the difference between the birefringence of pure and D-serine doped TGS changes its sign, is a special result, which may be used for the study of the admixture distribution by the optical method.

Decrease in temperature leads to an increase in the birefringence $\Delta \mathrm{n}_{\mathrm{i}}(\mathrm{i}=\mathrm{x}, \mathrm{y}, \mathrm{z})$ in three crystallographic directions (Fig. 6).

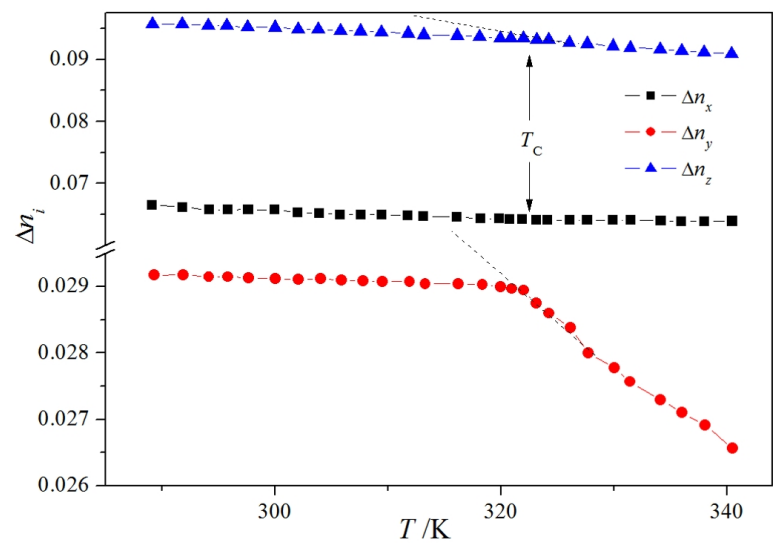

Fig. 6. Temperature dependences of birefringence $\Delta \mathrm{n}_{\mathrm{i}}(\mathrm{T})(\mathrm{i}=\mathrm{x}, \mathrm{y}, \mathrm{z})$ of TGS $+\mathrm{D}$-serine at the wavelength $\lambda=500 \mathrm{~nm}$.

The dependences $\Delta \mathrm{n}_{\mathrm{i}}(\mathrm{T})(\mathrm{i}=\mathrm{x}, \mathrm{y}, \mathrm{z})$ are linear in the paraelectric phase and are characterized by small nonlinearities in the polar one. The main parameters of pyroelectrical sensors obtained on the basis of TGS and TGS + D-serine crystals are presented in Table 1 . Here, $\varepsilon$ is dielectric permittivity of a crystal in the paraelectric phase, $\gamma$ is pyroelectric coefficient, $\mathrm{c}$ is heat capacity, $\operatorname{tg} \delta$ is a measure of dielectric losses, $\mathbf{M}_{1}=\frac{\gamma}{c}, \mathbf{M}_{2}=\frac{\gamma}{\mathrm{c}} \varepsilon$ and $\mathbf{M}_{3}=\frac{\gamma}{\mathrm{c}}(\varepsilon \cdot \operatorname{tg} \delta)$ are figures of merit related to the pyroelectric effect. The larger are the coefficients $M_{1}$, $\mathrm{M}_{2}$ and $\mathrm{M}_{3}$, the better the crystal is as a pyroelectric material.

The main advantage of TGS $+\mathrm{D}$-serine as a material for pyroelectric sensor in comparison to pure TGS is the high coercive field. This leads to a decrease of the relative instability of pyroelectric material what is seen in Table 1. Also, TGS + Dserine is similar to linear pyroelectrics. An increase in the coercive field of TGS + D-serine in comparison to pure TGS may be associated with the corresponding decrease of the optical anisotropy observed in the present study upon the transition from TGS to TGS + D-serine. 
Table 1. Influence of D-serine admixture on the pyroelectric parameters of TGS at room temperature.

\begin{tabular}{cccccccc}
\hline Material & $\varepsilon$ & $\operatorname{tg} \delta$ & $\gamma \times 10^{4}$ & $\begin{array}{c}\mathrm{M}_{1} \times 10^{10} \\
\mathrm{C} /\left(\mathrm{m}^{2} \cdot \mathrm{K}\right)\end{array}$ & $\begin{array}{c}\mathrm{M}_{2} \times 10^{10} \\
\mathrm{C} \cdot \mathrm{m} / \mathrm{J}\end{array}$ & $\begin{array}{c}\mathrm{M}_{3} \times 10^{10} \\
\mathrm{C} \cdot \mathrm{m} / \mathrm{J}\end{array}$ & $\begin{array}{c}\text { Relative instability, \% } \\
\mathrm{C} \cdot \mathrm{m} / \mathrm{J}\end{array}$ \\
\hline \hline TGS & 40 & 0.1 & 3.5 & 1.4 & 3.5 & 0.7 & 60 \\
TGS + 5\% D-serine & 47 & 0.085 & 1.6 & 0.64 & 1.4 & 0.3 & 8 \\
\hline
\end{tabular}

\section{Conclusions}

Magnitudes of the principal refractive indices of TGS + D-serine crystals, $n_{x}, n_{y}$, and $n_{z}$, were found to be close to those for pure TGS. This may be explained by the close chemical compositions of these substances. However, the temperature dependences of refractive indices and birefringence of TGS + D-serine differ from the analogous values of TGS more substantially. This may be related to different stability of the unipolar state of these materials.s

The experimental results obtained in this study will be necessary as the reference data for the comparison with the calculated refractive indices of TGS + D-serine. These refractive indices will be obtained by using the density functional theory (DFT) based calculation codes. The corresponding computer simulation runs will be done for different positions of D-serine molecules within the TGS unit cell. Determination of the proper position of D-serine, should reveal the features of TGS + D-serine crystal structure necessary to achieve stable unipolarity.

\section{References}

[1] Choe H.M., Judy J.MH., van der Ziel A., Ferroelectrics, 15 (1977), 181.

[2] Kremenchugski L.S., Rojtsina O.V., Pyroelectric detectors of radiation, Kiev, Naukova Dumka, 1979.

[3] Kremenchugski L.S., Rojtsina O.V., Pyroelectric reception devices, Kiev, Naukova Dumka, 1982.

[4] BeERMAN H.P., Opt. Laser Technol., 9 (1977), 38.

[5] Blakburn H., Syst. Technol., 2 (1977), 15.

[6] Predham M.M., Gerg R.K., Opt. Commun., 20 (1977), 422.

[7] Predham M.M., Gerg R.K., Ferroelectrics, 15 (1977), 195.

[8] Shaulov A., Ferroelectrics, 15 (1977), 203.

[9] SINGH V.P., ZIEL VAN DER A., Ferroelectrics, 15 (1977), 135.
[10] Kladkevich M.D., KRemenchugski L.S., SAMOILOV V.B., Thermal radiation detectors, Leningrad, GOI, 1978.

[11] Seliuk B.V., Phys. Solid State, 20 (1978), 570.

[12] Felix P., Gamot P., LacheaV P., RaVerdy Y., Ferroelectrics, 17 (1978), 543.

[13] Milovidova S.D., Burdanina N.A., Kamysheva L.N., Gridniev S.A., Verkhovets A.K., Ferroelectrics and Piezoelectrics, Kalinin University, Kalinin, 1977.

[14] McNaught A.D., Wilkinson A. (Eds.), IUPAC. Compendium of Chemical Terminology, $2^{\text {nd }}$ ed., Blackwell Scientific Publications, Oxford, 1997.

[15] Stankowska J., Czarnecka A., Kwitkowska G., Ferroelectrics, 108 (1990), 325.

[16] Stankowska J., Bochynski Z., Czarnecka A., DEJNEKA L., Ferroelectrics, 124 (1991), 55.

[17] Smolin Yu.I., LAPShin A.E., Drozdova I.A., Phys. Solid State, 44 (2002), 1881.

[18] Smolin Yu.I., Lapshin A.E., Pankova G.A., Phys. Solid State, 45 (2003), 1803.

[19] Stankowska J., Czarnecka A., Dratwinska A., Ferroelectrics, 140 (1993), 65.

[20] Stankowska J., Czarnecka A., Bangobango Dongo Gemi, Acta Phys. Pol. A, 83 (1993), 485.

[21] Romanyuk M.O., Andriyevsky B.V., StadnyK V.YO., Kushnir O.S., J. Phys. Stud., 17 (2013), 3701.

[22] RomanyuK M.O., Workshop on crystal-and-physics and crystal-and-optics. Lviv, Publishing Center of the Ivan Franko, National University of Lviv, 2012.

[23] TSEDRIK M.S., Ferroelectrics and Piezoelectrics, Kalinin University, Kalinin, 1982.

[24] Romanyuk N.A., Kostetski A.M., Ukr. Phys. J., 22 (1977), 965.

[25] Romanyuk N.A., Kostetski A.M., Viblyi I.F., Ukr. Phys. J., 21 (1976), 207.

[26] Lomova L.G., Sonin A.S., Regulskaya G.A., Sov. Phys. Crystallogr., 13 (1969), 90.

[27] XU Y., Ferroelectric materials and their applications, North-Holland, Amsterdam, 1991, p. 296.

[28] AndriyeVsKy B., KARDASH V., DACKo S., CZAPLA Z., Acta Phys. Pol. A, 99 (2001), 593.

Received 2014-09-25 Accepted 2015-09-04 